\title{
Geotechnique
}

\section{PC-based and MgO-based binders stabilised/solidified heavy metal contaminated model soil: Strength and heavy metal speciation in early stage \\ --Manuscript Draft--}

\begin{tabular}{|c|c|}
\hline Manuscript Number: & 17-P-194R1 \\
\hline Full Title: & $\begin{array}{l}\text { PC-based and MgO-based binders stabilised/solidified heavy metal contaminated } \\
\text { model soil: Strength and heavy metal speciation in early stage }\end{array}$ \\
\hline Article Type: & Technical Note \\
\hline Corresponding Author: & $\begin{array}{l}\text { fei wang } \\
\text { Southeast University } \\
\text { Nanjing, jiangsu CHINA }\end{array}$ \\
\hline \multicolumn{2}{|l|}{$\begin{array}{l}\text { Corresponding Author Secondary } \\
\text { Information: }\end{array}$} \\
\hline Corresponding Author's Institution: & Southeast University \\
\hline \multicolumn{2}{|l|}{$\begin{array}{l}\text { Corresponding Author's Secondary } \\
\text { Institution: }\end{array}$} \\
\hline First Author: & Fei Wang \\
\hline \multicolumn{2}{|l|}{ First Author Secondary Information: } \\
\hline \multirow[t]{3}{*}{ Order of Authors: } & Fei Wang \\
\hline & Zhengtao Shen \\
\hline & Abir Al-Tabbaa \\
\hline \multicolumn{2}{|c|}{ Order of Authors Secondary Information: } \\
\hline Abstract: & $\begin{array}{l}\text { The investigation of using PC-based and MgO-based binders in treating contaminated } \\
\text { model soil was carried out to study the benefit of novel binders over conventional ones } \\
\text { in Stabilisation/Solidification systems ( } / \mathrm{S} \text { ), as well as their involved binding } \\
\text { mechanism. Binders used in this study include Portland cement (PC), ground } \\
\text { granulated blastfurnace slag (GGBS), pulverised fly ash (PFA) and magnesia (MgO). } \\
\text { The strength and the leaching properties of S/S treated samples via unconfined } \\
\text { compressive strength (UCS) and sequential extraction tests are presented. The results } \\
\text { showed that the early-age strength of these mixes is influenced by the reactivity of } \\
\text { binders; heavy metals were principally distributed in the carbonate and the Fe-Mn } \\
\text { oxide fractions in all mixes after 28-days curing time; the speciation distribution } \\
\text { characteristics are not the same among } \mathrm{Zn}, \mathrm{Cu}, \mathrm{Ni} \text { and } \mathrm{Pb} \text {; and the stability of } \mathrm{Zn}, \mathrm{Cu} \text {, } \\
\mathrm{Ni} \text { and } \mathrm{Pb} \text { benefits from a longer curing time and the usage of } \mathrm{MgO} \text {. }\end{array}$ \\
\hline \multirow[t]{4}{*}{ Suggested Reviewers: } & $\begin{array}{l}\text { Krishna R Reddy } \\
\text { University of Illinois at Chicago } \\
\text { kreddy@uic.edu } \\
\text { an expert in this area }\end{array}$ \\
\hline & $\begin{array}{l}\text { Jeffrey C. Evans } \\
\text { Bucknell University } \\
\text { evans@bucknell.edu } \\
\text { expert in stablisation/solidification }\end{array}$ \\
\hline & $\begin{array}{l}\text { Ningjun jiang } \\
\text { University of Hawai'i at Manoa } \\
\text { jiangn@hawaii.edu } \\
\text { working on this research area for many years }\end{array}$ \\
\hline & $\begin{array}{l}\text { Sônia Denise Ferreira Rocha } \\
\text { Universidade Federal de Minas Gerais } \\
\text { sdrocha@demin.ufmg.br } \\
\text { working on this area for many years }\end{array}$ \\
\hline
\end{tabular}


Opposed Reviewers:

Additional Information:

Question

Response

Please enter the total number of words in 2000

the main text only.

The main text of the paper should be as concise as possible. The word count of General Papers should not exceed 5000 words and for Technical Notes should not exceed 2000 words.

The word count of a submission excludes the abstract, list of notation, acknowledgements, references, tables and figure captions.

Discussions, Book Reviews, and Obituaries should be less than 1000 words.

Whilst Geotechnique reserves the right to publish papers of any length Authors should be aware that any submission for a General Paper that is significantly over the word limit will be subjected to preassessment and may be returned to the Authors for editing prior to being sent for review.

The word limit for Technical Notes will be strictly adhered to, and if over 2000 words, the submission will be considered as a General Paper.

Have you included a full notation list including definitions (and SI units of measurement where appropriate) for any mathematical terms and equations included in your paper?

Have you included a completed copyright Yes transfer form? This is required for all publications and can be found here.

Have you uploaded each of your figures separately and in high-resolution .tiff (ideal for photographs) or .eps files (best for line drawings)? This is required for all figures before your paper can be accepted. Our figure requirements can be found here.

Have you uploaded your tables in an
editable Microsoft Word (.doc) format?

Have you included a separate list of all Yes your figure and table captions?

Are your figures clear when printed in black and white? (For example, are plot lines distinguishable; are tints sequentially graded?) As this journal is printed in black and white, any figures that are unclear may be removed.

Are your references in Harvard style? Our Yes reference guidelines can be found here. 
To ensure your paper is indexed correctly sequential extraction, MgO, GGBS, stabilization/solidification, strength - and therefore as discoverable as

possible - in our ICE Virtual Library,

please choose up to 6 keywords from our

Keywords List. This can be found here.

We are unable to accept keywords that do not appear on this list. 


\title{
PC-based and MgO-based binders stabilised/solidified heavy metal contaminated model soil: Strength and heavy metal speciation in early stage
}

\author{
Fei Wang ${ }^{a, b, *, Z h e n g t a o}$ Shen $^{b, c,}$ and Abir Al-Tabbaa ${ }^{b}$ \\ anstitute of Geotechnical Engineering, School of Transportation, Southeast \\ University, Nanjing, 210096, China \\ ${ }^{b}$ Department of Engineering, University of Cambridge, Trumpington Street, \\ Cambridge, CB2 1PZ, UK \\ ${ }^{\mathrm{c}}$ Department of Earth and Atmospheric Sciences, University of Alberta, Edmonton, \\ T6G 2E3, Canada \\ *Corresponding author. Tel.: 086-18801580801 \\ E-mail address: fwtiffany@gmail.com (F. Wang)
}

A Paper Submitted for possible Publication as Technical Notes to Geotechnique. 
ABSTRACT: The investigation of using PC-based and MgO-based binders in treating contaminated model soil was carried out to study the benefit of novel binders over conventional ones in Stabilisation/Solidification systems (S/S), as well as their involved binding mechanism. Binders used in this study include Portland cement (PC), ground granulated blastfurnace slag (GGBS), pulverised fly ash (PFA) and magnesia $(\mathrm{MgO})$. The strength and the leaching properties of $\mathrm{S} / \mathrm{S}$ treated samples via unconfined compressive strength (UCS) and sequential extraction tests are presented. The results showed that the early-age strength of these mixes is influenced by the reactivity of binders; heavy metals were principally distributed in the carbonate and the Fe-Mn oxide fractions in all mixes after 28-days curing time; the speciation distribution characteristics are not the same among $\mathrm{Zn}, \mathrm{Cu}, \mathrm{Ni}$ and $\mathrm{Pb}$; and the stability of $\mathrm{Zn}, \mathrm{Cu}, \mathrm{Ni}$ and $\mathrm{Pb}$ benefits from a longer curing time and the usage of $\mathrm{MgO}$.

Keywords: sequential extraction, $\mathrm{MgO}$, GGBS, stabilization/solidification, strength 


\section{INTRODUCTION}

Stabilisation/Solidification (S/S) has been widely used to remediate contaminated soils over the past a few decades especially in the US, UK and Netherlands. According to "2014-2020 China Soil Remediation Market (2014)", around 28\% of contaminated sites in China has been remediated using S/S (Du et al., 2014; Quina et al., 2014; Wang et al., 2014; Wang et al., 2015a). Extensive studies have been focused on cement-based S/S, as cement produces high strength, low permeability, and has potential to neutralize acidic wastes and precipitate heavy metals into insoluble hydroxides (La Grega et al., 2001). However, it was argued that magnesia-based binders have advantages over cement-based binders and provide additional unique benefits (Shand, 2006; Al-Tabbaa, 2013). $\mathrm{MgO}$ was considered as having superior advantages in immobilising a wide range of contaminants because of its $\mathrm{pH}$ neutralisation range (9-11), has good ion-exchange ability and strong complexation ability to metal ions (Jin et al., 2015). The application of $\mathrm{MgO}$ in stabilising/solidifying contaminated soils is a recently development (Garcia et al., 2004; Jin et al., 2015). Iyengar (2008) used MgO-PFA blend to treat $\mathrm{Zn}$ contaminated soil and found its $\mathrm{Zn}$ immobilisation degree was significantly higher that of PC-PFA blend. Goodarzi and Movahedrad (2017) compared the performance of ground granulated blast-furnace slag (GGBS) alone and the slag activated with cement (C-GGBS) and $\mathrm{MgO}$ (M-GGBS) treated $\mathrm{Zn}$ contaminated clayey soil and found that $\mathrm{MgO}$ gives a better cementation structure-bonding and $\mathrm{pH}$-buffering capacity to the slag-amended soil. Du et al. (2016) investigated the impact of drying-wetting cycle on the engineering properties of GGBS-MgO stabilised low plasticity clay and claimed that the GGBS-MgO stabilised clay display higher dry density and lower mass loss than the PC stabilised clay. Therefore, MgO-based binders are promising materials for $\mathrm{S} / \mathrm{S}$.

Sequential extraction chemical test provides detailed information about the origin, mode of occurrence, biological and physicochemical availability, mobilisation and transport of trace metals (Filgueiras, 2002). Using sequential extraction test to study heavy metals' speciation is able to enhance stakeholders' confidence in $\mathrm{S} / \mathrm{S}$. Zhang et 
al. (2011) investigated the impact of different agents in stabilising heavy metal contaminated clayish soil, and reported that metal speciation involved numerous mechanisms based on metal's properties, species and the interference between metals. Li et al. (2001) studied the binding mechanisms and chemical partitioning of $\mathrm{Zn}$ in cement-based stabilised wastes. Their results showed that the leaching of $\mathrm{Zn}$ from the cement treated waste took place at the second and the third extraction steps. Wang et al. (2014) investigated the metal speciation of 17-year-old cement-based binders stabilised field soil and claimed that the leaching of heavy metals occurred at the third extraction step. All of the above mentioned studies show the function of sequential extraction in exploring binding mechanisms of heavy metals. However, rare study can be found on the application of sequential extraction in $\mathrm{MgO}$-based binder treated samples.

Accordingly, this study compares the strength and heavy metal speciation of PC-based and MgO-based binders treated contaminated model soil in their early age. The detailed objectives were: 1) strength; 2) estimate the mobility of $\mathrm{Cu}, \mathrm{Ni}, \mathrm{Zn}$ and $\mathrm{Pb}$ in these samples; 3) compare $\mathrm{MgO}$-based binders with $\mathrm{PC}$-based binders in stablised/solidified contaminated soil and understand their binding mechanisms of heavy metals.

\section{MATERIAL AND METHODS}

The model soil was made from sharp sand, silica flour and kaolin; the composition of which was 91\%:4\%:5\%. The values were based on site soils investigated in previous studies (SMiRT project) (Wang et al.2015b; Wang et al.2016). The particle sizes of sharp sand are ranging from 0.07 to $4 \mathrm{~mm}$ with a median particle size (D50) of $\sim 0.75$ $\mathrm{mm}$. The chemical composition of kaolin and silt is detailed in Table S1. The particle size distribution of the model soil is detailed in Abunada (2015). The moisture content of the model soil used in this study was $10 \%$ by weight. According to the maximum concentrations of $\mathrm{Cu}, \mathrm{Ni}, \mathrm{Zn}$ and $\mathrm{Pb}$ in site soils from previous studies (Wang et al. 2014; Wang et al.2015a), a relative high contamination level of these metals was determined at 1500,1200, 1600 and $2500 \mathrm{mg} / \mathrm{kg}$ soil, respectively. 
PC(CEM I, 52.5N), PFA, GGBS and MgO were used as binders here. The detailed compositions of these binders are listed in Wang (2015). The mix design is based on Wang et al.(2015a) and is shown in Table 1.

Table 1.Soil-binder constituents in percentage weight of the laboratory treated model soil (wt $\%)$.

\begin{tabular}{|c|c|c|c|c|c|c|c|}
\hline & \multirow{2}{*}{ No } & \multicolumn{4}{|c|}{ Binder components ratio } & \multirow{2}{*}{ Soil } & \multirow{2}{*}{ Water } \\
\hline & & PC & MgO & GGBS & PFA & & \\
\hline \multirow{3}{*}{$\begin{array}{l}\text { PC-based } \\
\text { mixes }\end{array}$} & $\mathrm{P}$ & 8.4 & - & - & - & 83.3 & 8.3 \\
\hline & $\mathrm{PF}$ & 4.2 & - & - & 4.2 & 83.3 & 8.3 \\
\hline & PG & 4.2 & - & 4.2 & - & 83.3 & 8.3 \\
\hline \multirow{3}{*}{$\begin{array}{l}\text { MgO-based } \\
\text { mixes }\end{array}$} & $\mathrm{M}$ & - & 8.4 & - & - & 83.3 & 8.3 \\
\hline & $\mathrm{MF}$ & - & 4.2 & - & 4.2 & 83.3 & 8.3 \\
\hline & MG & - & 4.2 & 4.2 & - & 83.3 & 8.3 \\
\hline
\end{tabular}

The specimen preparation was carried out in laboratory and was closely followed the description in ASTM D1632-07 (2007). The detailed mixing work can be found in supporting information. After being prepared, the specimens were cured under the relative humidity of $\sim 99 \%$ and temperature of $20^{\circ} \mathrm{C} \pm 2^{\circ} \mathrm{C}$. These samples were then de-moulded after 9 days and 28 days.

The unconfined compressive strength (UCS) of the stablilised/solidified soil was determined using the UCS test in accordance with the ASTM D4219-08. The details of UCS and sequential extraction tests are shown in supporting information and can be found in Wang et al. (2014).

\section{RESULTS AND DISCUSSION}

\subsection{Bulk Density and UCS}

The bulk densities of two group mixes are presented in Fig. 1 showing generally a consistent range of $2215 \mathrm{~kg} / \mathrm{m}^{3}$ to $2285 \mathrm{~kg} / \mathrm{m}^{3}$ at 28 days. Figure 2 shows the corresponding average UCS values of mixes at 28 days. The deviation of these values is in the range of 0.01-0.63 MPa. It can be seen that $\mathrm{P}$ produced the highest strength at 28 days $(\sim 1000 \mathrm{kPa})$. This was followed by $\mathrm{M}, \sim 660 \mathrm{kPa}$. The strength values of MF and MG are lower than M, at $\sim 200 \mathrm{kPa}$. Mixes PF and PG are the weakest, <70kPa. 
Only $\mathrm{P}$ and $\mathrm{M}$ are able to produce enough strength as required in the Environment Canada WTC (440 kPa) for controlled utilisation (Stegemann \& Cote, 1996).

Since the early-age strength of binders is known to be influenced by the reactivity of cement blends ( $\mathrm{Li} \&$ Zhao, 2003), the reactivity of different materials is used here to explain samples' strength development. The reactivity was determined by the chemical modulus $\left([\mathrm{CaO}+\mathrm{MgO}] / \mathrm{SiO}_{2}\right)$ such that, the higher the value, the more reactive the binders are (Wainwright \& Rey, 2000). The reactivity of PC, MgO, GGBS and PFA used here was calculated at 4.6, 40.9, 1.3 and 0.17 in sequence (Wang, 2015).

Because the reactivity of PFA and GGBS is very low, and the presence of both PFA and GGBS was reported as retarding the hydration of PC at the early-age (Li \& Zhao, 2003; Zhang et al., 1998; Hogan \& Meusel, 1981), the early strengths of PF and PG were lower than the strength of $\mathrm{P}$ as shown in Fig. 2, equally the early strengths order is: $\mathrm{M}>\mathrm{MG}>\mathrm{MF}$. Although the strength of $\mathrm{Mg}(\mathrm{OH})_{2}$ (the main hydration product of $\mathrm{MgO}$ ) was found lower than that of the hydration products of PC, both MF and MG blends produced higher strengths than PF and PG blends respectively at 28 days. This agrees well with a paste study reported by Yi et al.(2013) that the reactive MgO activated GGBS achieved higher 28-day compressive strength than that of the equivalent $\mathrm{Ca}(\mathrm{OH})$ 2-GGBS system due to the larger content of the voluminous hydrotalcite-like phases formed. Although $\mathrm{MgO}$ was found more efficient in activating GGBS compared to PC (Jin, 2014), $\mathrm{MgO}$ was not fully consumed in $\mathrm{MG}$, as strong peaks of $\mathrm{MgO}$ was identified in MgO-GGBS at a ratio of 1:1, by X-ray diffraction (XRD) test (Yi et al.,2013). The unhydrated $\mathrm{MgO}$ may cause cracks in the treated samples, due to delayed expansions, hence reducing the strength of this mix. This is also one of the reasons why the strength of MG is lower than M at both time points. In Wang et al. (2015a), it was found that the average strength of the GGBS and $\mathrm{MgO}$ mixes at a ratio of 9:1 at 28 days in the SMiRT project was $\sim 3.2 \mathrm{Mpa}$, which is much higher than that of MG laboratory samples. This is due to the fact that 1) the high w/c ratio (the impact of w/c was studied in Wang (2015); 2) a ratio of 9:1 is identified as the best combination in MgO-GGBS blends. Yi et al. (2014) claimed that the strength of GGBS-MgO blends using 90\% GGBS is three times higher than that of blends using 50\% GGBS in stabilising uncontaminated soil. The 
reason of using 1:1 in the laboratory study was to keep consistent with the PC-based samples.

\subsection{Sequential extraction}

The recovery rate of sequential extraction was defined as a ratio of total concentrations from 5-step sequential extraction and the full acid digestion of these samples. The recovery rates of $\mathrm{Cu}, \mathrm{Ni}, \mathrm{Zn}$ and $\mathrm{Pb}$ are in the ranges of $72.7-99.2 \%$, 76.5-90\%, 78.6-92.1\% and 73-94.5\%, respectively.

After 28-days curing, the percentages of heavy metals obtained from the extractable, carbonate, Fe-Mn oxide, organic matter and residual phases from each sample were calculated and discussed in this study. In Fig.3, it is clear that heavy metals after 28-days curing time are principally distributed in the second and third fractions.

The percentages of $\mathrm{Zn}$ in the extractable, organic matter and residual phases are very low compared to their starting concentrations. Clearly, except $\sim 60 \% \mathrm{Zn}$ in $\mathrm{M}$ was found mainly bounded to the $\mathrm{Fe} / \mathrm{Mn}$ oxide phase, it was principally dissolved in the carbonate phase in other mixes, at a range of $\sim 78 \%-90 \%$ (Fig. 3a). The high percentage of $\mathrm{Zn}$ in the carbonate phase is due to the dissolution of $\mathrm{ZnO}$ and other $\mathrm{Zn}$-cement hydration products (Li et al., 2001a). Since PFA and GGBS retard the hydration of PC (Zhang et al., 1998; Hogan and Meusel, 1981; Li and Zhao, 2003), PF and PG leached more $\mathrm{Zn}$ in the carbonate phase than $\mathrm{P}$. In addition, the high percentage of $\mathrm{Zn}$ leached from PF and MF in the second extraction step was in agreement with Li et al. (2001a) that PFA has negative effects on immobilising Zn. Compared to other mixes, $\mathrm{M}$ was selected as the most effective mix in treating $\mathrm{Zn}$, as $\sim 60 \%$ of $\mathrm{Zn}$ in $\mathrm{M}$ leached from the third extraction step. MG was less effective than $M$ in immobilising $\mathrm{Zn}$, while Wang et al., (2015a) reported that MgO-GGBS blend works better than M. This is because the field condition is different with the laboratory one, and the ratios of MgO-GGBS used in two studies are different at 1:1 and 1:9, respectively. It was reported by Jin and Al-Tabbaa (2014) that unreacted $\mathrm{MgO}$ was identified from $\mathrm{MgO}-\mathrm{GGBS}$ paste and suggested that the slag hydration did not fulfil. Hence, the residual unhydrated $\mathrm{MgO}$ together with these did not fully consumed slag hydration may be the cause of the 
higher percentage of $\mathrm{Zn}$ in the second extraction step in $\mathrm{MG}$ compared to that in $\mathrm{M}$ (Yi et al., 2014a).

In Fig. 3b, $\sim 25 \% \mathrm{Cu}$ in $\mathrm{PG}$ and $\sim 30 \% \mathrm{Cu}$ in $\mathrm{MG}$ were extracted from the fourth step instead of the third step. Although $\mathrm{Cu}$ was reported as more stable with organic matter, the presence of organics in the model soil is very low. The possible explanation is because of the existence of $\mathrm{Cu}$-hydrotalcite $\left(\mathrm{Mg}_{6} \mathrm{Al}_{2} \mathrm{CO}_{3}(\mathrm{OH})_{16} \cdot 4 \mathrm{H}_{2} \mathrm{O}\right)$-like phases (Ht) complex, one of the hydration product of PG and MG detected by XRD and scanning electron microscopy (SEM) (Yi et al., 2014b), is more stable than other hydration products.

In Fig.3c, the percentage of $\mathrm{Ni}$ in MF presents the highest value in the carbonate fraction indicates that more Ni can be easily released from MF. The effectiveness of $\mathrm{M}$ is not as significant as its function in immobilising $\mathrm{Zn}, \mathrm{Cu}$ and $\mathrm{Pb}$. In Fig.3d, 0.4-3.8\% of $\mathrm{Pb}$ was found from extractable phase. This agrees well with Wang et al., (2014)'s study that $\mathrm{Pb}$ was more mobile than $\mathrm{Zn}, \mathrm{Cu}$ and $\mathrm{Ni}$. In the alkali environment, $\mathrm{Pb}$ precipitates into lead hydroxide, which then was transformed into a more insoluble $\mathrm{PbO}$ phase (Li et al., 2001b), together with its adsorption binding mechanism, it was mainly released in the secondary extraction step. The benefit of using $\mathrm{M}$ and $\mathrm{MG}$ in immobilsing $\mathrm{Pb}$ is significant (Fig. 3d).

The sequential extraction results of S/S samples under 9 and 28 days' curing time are displaced in Fig. 4 to study the effect of curing time. The raise of percentages leached in the third/forth fraction suggesting that the stability of these metals benefits from a longer curing time.

\section{CONCLUSIONS}

The present study investigated the strength and heavy metal speciation of stabilized/solidified heavy metals contaminated model soil using PC-based and MgO-based binders. This study found that:

- The early-age strength of samples is influenced by the reactivity of the binders, where $\mathrm{P}$ (PC only), $\mathrm{M}$ ( $\mathrm{MgO}$ only) produced higher strength than other mixes;

- After 28-days curing time, heavy metals were principally distributed in the carbonate 
and the Fe-Mn oxide fractions in all mixes;

- GGBS put a significant impact on the $\mathrm{Cu}$ distribution in treated soil.

- The speciation distribution characteristics of $\mathrm{Zn}, \mathrm{Cu}, \mathrm{Ni}$ and $\mathrm{Pb}$ are varied;

- $\quad \mathrm{MgO}$-based binders have advantages in treating heavy metals;

- $\quad$ The stability of $\mathrm{Zn}, \mathrm{Cu}, \mathrm{Ni}$ and $\mathrm{Pb}$ benefits from a longer curing time.

\section{Acknowledgements}

This research is financially supported by the National Natural Science Foundation of China, China (Grant No. 51608113). The second author would like to thank the Killam Trusts from Canada for kindly providing the Izaak Walton Killam Memorial Postdoctoral Fellowship.

\section{References}

Jiangsu (Yixing) Institute of Environmental Industry, (2014). 2014-2020 China Soil Remediation Market- A guide to the CNY 100 hundreds of billions, China: Jiangsu (Yixing) Institute of Environmental Industry.

Abunada,Z. (2015).Innovative soil mix technology constructed permeable reactive barrier for groundwater remediation. $\mathrm{PhD}$ thesis, University of Cambridge, UK.

Al-Tabbaa, A. (2013). Reactive magnesia cement. In:, Eco-efficient Concrete (eds Pacheco-Torgal, F. Jalali, S. Labrincha, J. John V.M.), pp. 523-543, Cambridge, UK: Woodhead Publishing Limited.

Du, Y. J. Wei, M. L. Reddy, K.R.Liu, Z. P. \& Jin, F.(2014). Effect of acid rain pH on leaching behavior of cement stabilized lead-contaminated soil. J. Hazard. Mater.271, 131-140.

Du, Y. J. Bo, Y. L. \& Jin, F., et al. (2016). Durability of reactive magnesia-activated slag-stabilized low plasticity clay subjected to drying-wetting cycle. Eur. J. Environ. Civ. En., 20, No. 2, 215-230.

Filgueiras, A.V. Lavilla, I. \& Bendicho C. (2002). Chemical sequential extraction for metal partitioning in environmental solid samples. J. Environ. Monit. 4, 823-857. 
Garcia, M.A. Chimenos, J.M. Fernandez, A.I. Miralles, L. Segarra, M.\& Espiell, F. (2004). Low-grade MgO used to stabilize heavy metals in highly contaminated soils. Chemosphere 56, 481-491.

Goodarzi, A. R. \& Movahedrad, M. (2017). Stabilization/solidification of zinc-contaminated kaolin clay using ground granulated blast-furnace slag and different types of activators. Appl. Geochem. 81, 155-165.

Hogan, F.J. \& Meusel, J.W. (1981). Evaluation for durability and strength development of a ground granulated blast furnace slag. Cem. Concr. Aggregates 3, $40-52$.

ISO (1995). ISO 11466: Soil quality - extraction of trace elements soluble in aqua regia. Genève Switzerland: International Organization for Standardization, 03-01.

Iyengar, S.R. (2008). Application of Two Novel Magnesia-Based Binders in Stabilisation/Solidification Treatment Systems. PhD thesis, University of Cambridge, UK.

Jin, F. (2014). Characterisation and performance of reactive MgO-based cements with supplementary cementitious materials. PHD Thesis, Cambridge University, UK.

Jin, F. \& Al-Tabbaa, A. (2014). Evaluation of novel reactive $\mathrm{MgO}$ activated slag binder for the immobilisation of lead and zinc. Chemosphere 117, 285-294.

Jin, F. Wang, F. \& Al-Tabbaa, A. (2015). Three-year performance of in-situ solidified/stabilised soil using novel MgO-bearing binders. Chemosphere 144, $681-688$.

La Grega, M.D. Buckingham, P.L. \& Evans, J.C. (2001). Stabilization and solidification, in: Hazardous Waste Management, 2nd edn. New York: McGraw-Hill Inc..

Li, G. \&Zhao, X. (2003). Properties of concrete incorporating fly ash and ground granulated blast-furnace slag. Cement \& Concrete Composites, 25, 293-299.

Li, X. D. Zhang, Y. M. \& Poon, C. S. et al. (2001a) Study of zinc in cementitious material stabilised/solidified wastes by sequential chemical extraction and microstructural analysis. Chem. Spec. Bioavailab. 13, No. 1, 1-7.

Li, X.D. Poon, C.S. Sun, H. Lo, I.M.C.\& Kirk, D.W. (2001b). Heavy metal speciation 
and leaching behaviors in cement based solidified/stabilized waste materials. $J$. Hazard. Mater. A82, 215-230.

Liska, M. (2009). Properties and applications of reactive magnesia cements in porous blocks. PHD Thesis, Cambridge University, UK.

Quina, M. J. Bordado, J. C. M. \& Quinta-Ferreira, R. M. (2014). Stabilisation/solidification of APC residues from MSW incineration with hydraulic binders and chemical additives. J. Hazard. Mater. 264, 107-116.

Roy, A. \& Cartledge, F.K. (1997). Long-term behaviour of Portland-cement electroplating sludge waste form in presence of Copper nitrate. J. Hazard. Mater. 52, 265-286.

Shand, M.A. (2006). The Chemistry and Technology of Magnesia, New York: Wiley.

Stegemann, J. A. Cote, P. L. (1996). A proposed protocol for evaluation of solidified wastes. Sci. Total Environ. 178, 103-110.

Wainwright, P.J.\& Rey, N. (2000). The influence of ground granulated blast furnace slag (GGBS) additions and time delay on the bleeding of concrete. Cem. Concr. Compos. 22, No. 4, 253-257.

Wang, F. Wang, H. \& Al-Tabbaa, A.(2014). Leachability and heavy metal speciation of 17-year old stabilised/solidified contaminated site soils. J. Hazard. Mater. 278, $144-151$.

Wang, F. (2015). Time-related performance of soil mix technology stabilized/solidified soils from two contaminated sites. PHD Thesis, Cambridge University, UK.

Wang, F. Wang, H. \& Al-Tabbaa, A. (2015a). The performance of blended conventional and novel binders in the in-situ stabilization/solidification of a contaminated site soil. J. Hazard. Mater. 285, 46-52.

Wang, F. Wang, H. \& Al-TabbaaA. (2015b). Time-dependent performance of soil mix technology stabilised/ solidified contaminated site soils. J. Hazard. Mater. 286, 503-508.

Wang, F. Jin, F. Shen, Z. \& Al-Tabbaa, A. (2016). Three-year performance of in-situ mass stabilised contaminated soils using novel MgO-bearing binders. J. Hazard. 
Mater. 318, 302-307.

Yi, Y. Liska, M. \& Al-Tabbaa, A. (2013). Properties and microstructure of GGBS-magnesia pastes. Adv. Cem. Res. 26, No. 2, 114-122.

Yi, Y. Liska, M. \& Al-Tabbaa, A. (2014a). Properties of two model soils stabilized with different blends and contents of GGBS, MgO, lime, and PC. J. Mater. Civ. Eng. 26, 267-274.

Yi, Y. Li, C. Liu S. \& Al-Tabbaa, A. (2014b). Resistance of MgO-GGBS and CS-GGBS stabilised marine soft clays to sodium sulfate attack. Geotechnique 64, No. 8, 673-679.

Zhang, X. Yang, Y. Wong, C.L. \& Ong, C.K. (1998). Study of hydration of OPC/PFA blend with various activators using microwave technique. J. mater. sci. 33, 4191-4199.

Zhang, W. Tong, L. \& Yuan, Y. et al. (2011). Metal mobility and fraction distribution in a multimetal contaminated soil chemically stabilized with different agents. $J$. Hazard. Toxic Radioact. Waste 15, No. 4, 266-274.

\section{List of Figure Captions}

Fig. 1.The average density values of mixes at 28 days

Fig. 2. The average UCS values of mixes at 28days

Fig. 3. Percentage of heavy metals dissolved from different fraction at 28 days' curing time for (a) $\mathrm{Zn}$; (b) $\mathrm{Cu}$;(c) $\mathrm{Ni}$ and (d) $\mathrm{Pb}$

Fig. 4. Percentage of heavy metals dissolved from different fraction as a function of time for a) $\mathrm{Zn}$; b) $\mathrm{Cu}$; (c) $\mathrm{Ni}$ and (d) $\mathrm{Pb}$ 


\section{Geotechnique}

Journals Department

\section{Dear Editors:}

Enclosed is the revised version of the paper entitled "PC-based and $\mathrm{MgO}$-based binders stabilised/solidified heavy metal contaminated model soil: Strength and heavy metal speciation in early stage". I appreciated the constructive and thorough reviews provide by the journal and the positive response of both two reviewers that found the research of this manuscript is suitable for the Geotechnique. I have followed your suggestion and re-written this article into a technical note. In the revised paper, the manuscript count is cut into 2000 excluding the abstract, acknowledgements, references, figure and table legends. These changes I have made in response to reviewers' comments had been marked in Red in the body of the revised manuscript. Detailed response to their comments are as follows:

\section{Reviewer \#1:}

This paper presents an interesting study comparing a few $\mathrm{PC}$ and $\mathrm{MgO}$ mixtures for $\mathrm{S} / \mathrm{S}$ of several metals. The paper has the potential to be a contribution to the profession.

RESPONSE: We appreciate the positive comments about our manuscript.

The paper contains far too many grammatical errors to permit reader to fully engage in the paper. Please carefully edit this paper.

RESPONSE: Thank you for your review comment. These changes had been marked in Red in the body of the revised manuscript.

Secondly, the paper presents UC and leach test results and proceeds to identify various chemical mechanisms for any given specific result without evidence supporting the claim. No doubt the authors have reasons for the speculations but no evidence is provided in terms of test results on the specific formulations reported in the paper.

RESPONSE: Thank you so much for your very useful review comment. "detected by XRD and scanning electron microscopy (SEM)" was added in section 3.2 and was marked in Red. The findings of Yi and Jin (my previous research group members) using the X-ray diffraction (XRD) test and the scanning electron microscopy (SEM) test were used in this paper to explain my results. Later, I will follow your suggestion and do these kinds of tests myself. 
To this reviewer, that is a major technical flaw in the paper. Finally, the graphics are of low quality.

RESPONSE: Thank you for your review comment. This paper had been re-written into a technical note, and some efforts had been put on these graphics.

\section{Reviewer \#2:}

Present submission compares the strength and heavy metal speciation of PC-based and $\mathrm{MgO}-$ based binders treated heavy metal contaminated model soil in their early stage. The study is restricted to a specific model soil and to different maximum concentrations of four heavy metals: $\mathrm{Cu}, \mathrm{Ni}, \mathrm{Zn}$ and $\mathrm{Pb}$. Novelty in the manuscript is a small increment regarding previous publications of the authors. Background, mainly the use of Portland cement for $\mathrm{S} / \mathrm{S}$, is poor. So, it is the reviewer opinion that the manuscript should be enhanced and re-written as a technical note.

RESPONSE: Thank you a lot for your review comments. This paper had been re-written into a technical note.

Yours sincerely,

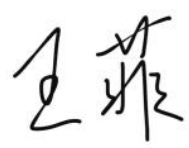

FeiWANG, Associate Prof.

Institute of Geotechnical Engineering

Southeast University

Email: 101012020@seu.edu.cn

Office Phone: +86 18801580801 


\section{Journal Publishing Agreement}

publishing

It is our policy to ask authors to assign the copyright of articles accepted for publication to the Publisher.

Exceptions are possible for reasons of national rules or funding. Please tick the relevant options below.

In assigning copyright to us, you retain all proprietary rights including patent rights, and the right to make personal (non-commercial) use of the article, subject to acknowledgement of the journal as the original source of publication.

By signing this agreement, you are confirming that you have obtained permission from any co-authors and advised them of this copyright transfer. Kindly note that copyright transfer is not applicable to authors who are opting to publish their papers as Open Access. Open Access authors retain copyright of their published paper.

Please complete the form below and return an electronic copy to your ICE Publishing contact:

(http://www.icevirtuallibrary.com/info/submit).

Journal name:.........................

Article title: ... PC-based and MgO-based binders stabilised/solidified heavy metal contaminated model soil: Strength and heavy metal speciation in early stage

Manuscript reference number:........1.7. P. 194 ......

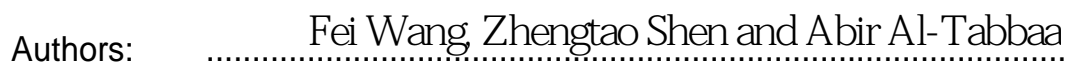

Your name: ….....ej.W.ang.......

Signature and date:

$2017 / 10 / 24$

Please tick either one option from part A or one option from part B. Please complete part C.

\section{A. Copyright}

$\square$ I hereby assign and transfer the copyright of this paper to Thomas Telford Ltd.

British Crown Copyright: I hereby assign a non-exclusive licence to publish to Thomas Telford Ltd.

I am a US Government employee: employed by (name of agency)

I am subject to the national rules of (country) ............................ and confirm that I meet their

requirements for copyright transfer or reproduction (please delete as appropriate)

\section{B. Authors with open access funding requirements. Please specify the Creative Commons license version required.}

$\square \quad$ CC-BY (for full details click here Creative Commons Attribution (CC BY) 4.0 International License)

CC-BY-NC-ND (for full details click here Creative Commons Attribution Non Commercial No-derivatives (CC BY NC ND) 4.0 International License)

\section{Please confirm that you have obtained permission from the original copyright holder. For ICE Publishing's copyright policy, please click here. ICE Publishing is a signatory to the STM Guidelines.}

I have obtained permission from the original copyright holder for the use of all subsidiary material included in this paper (E.g. for borrowed figures or tables). 


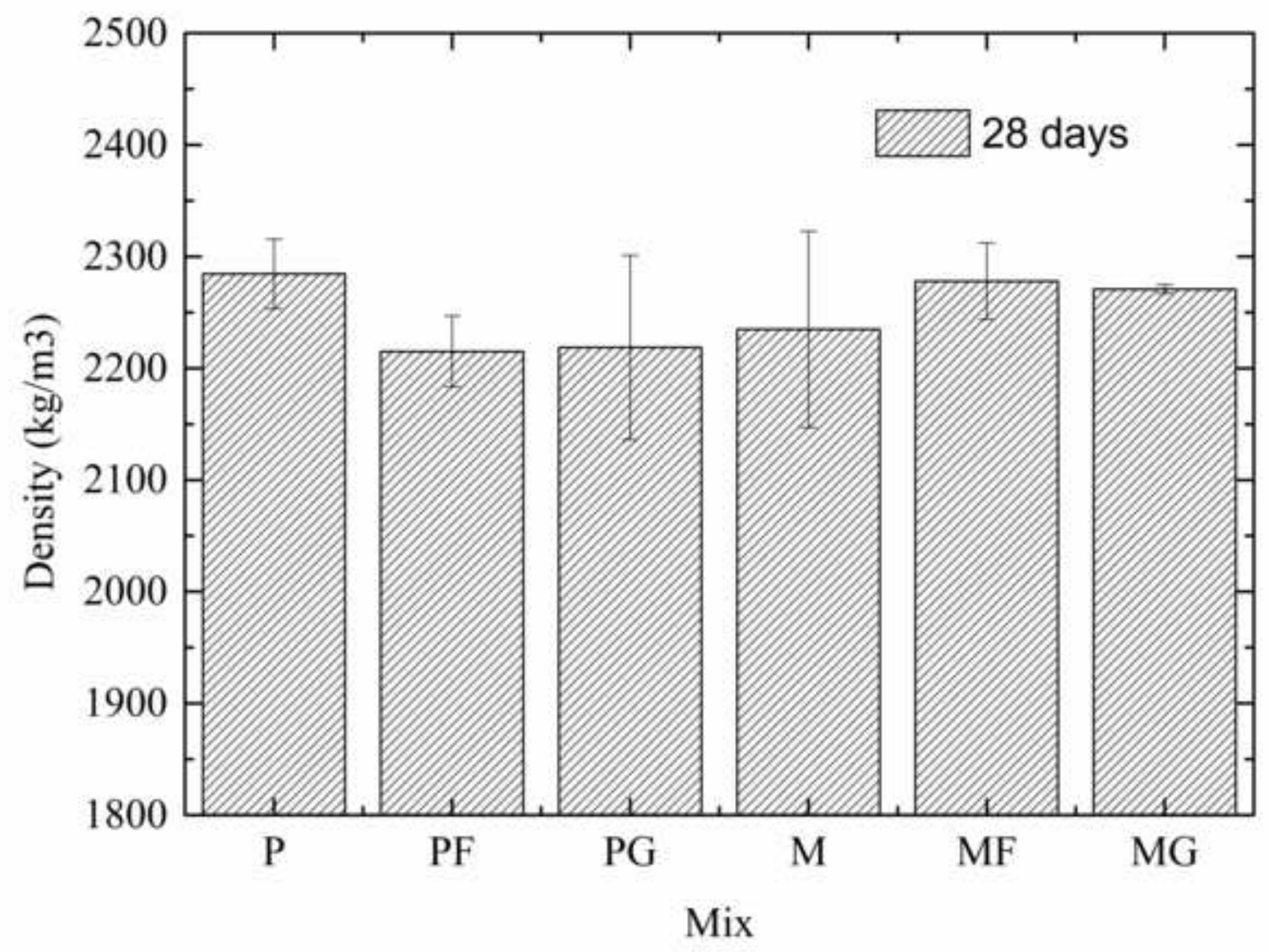




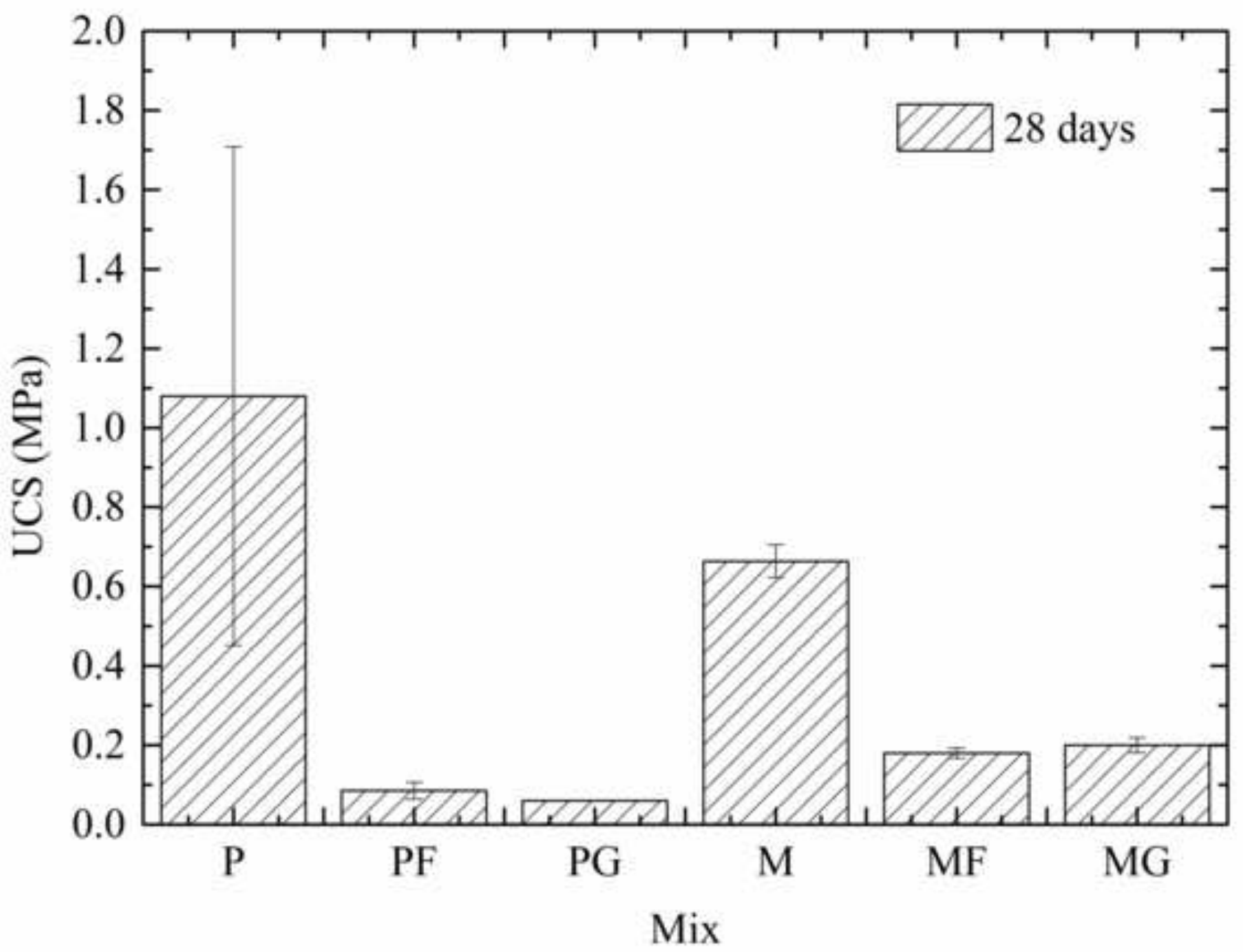




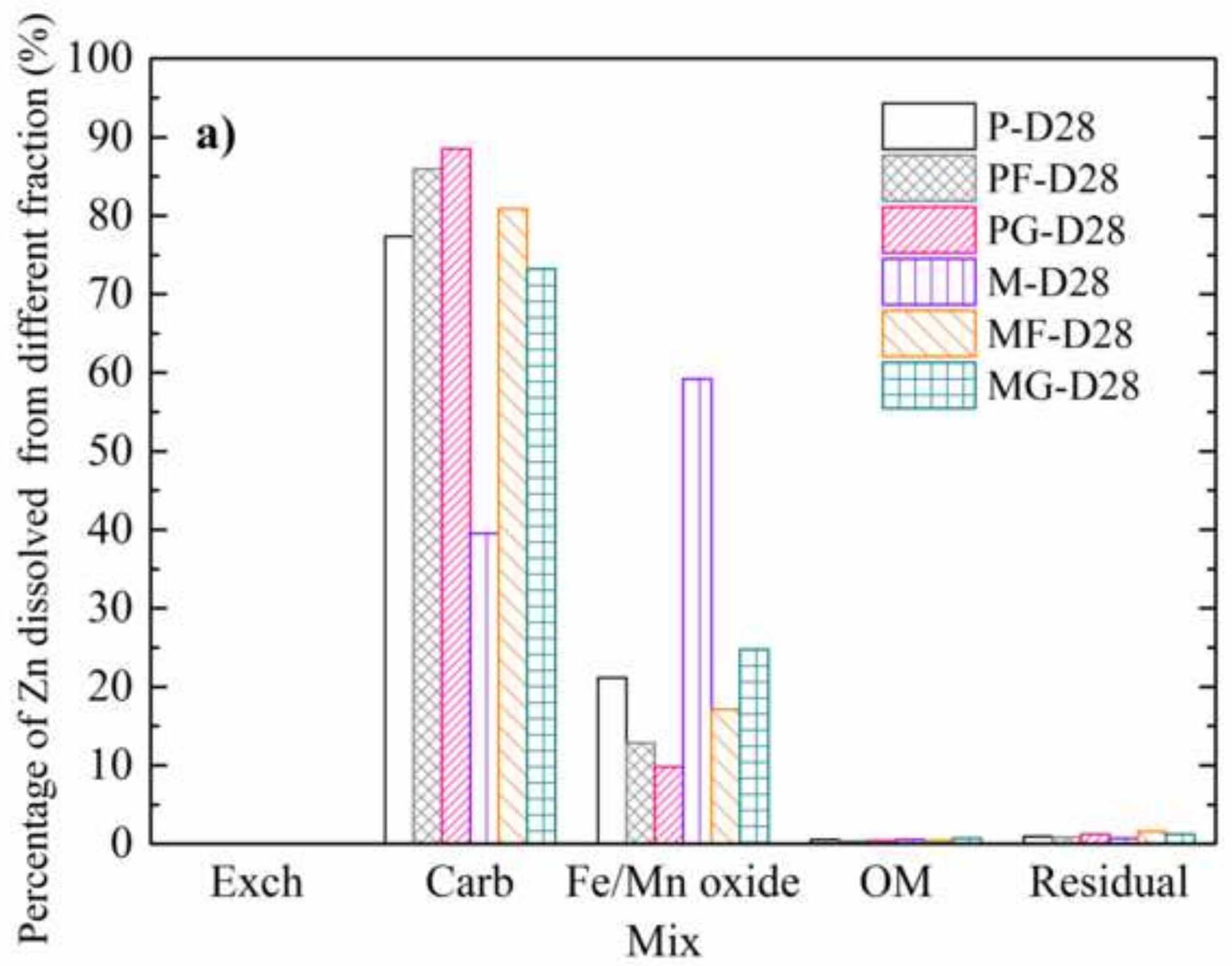




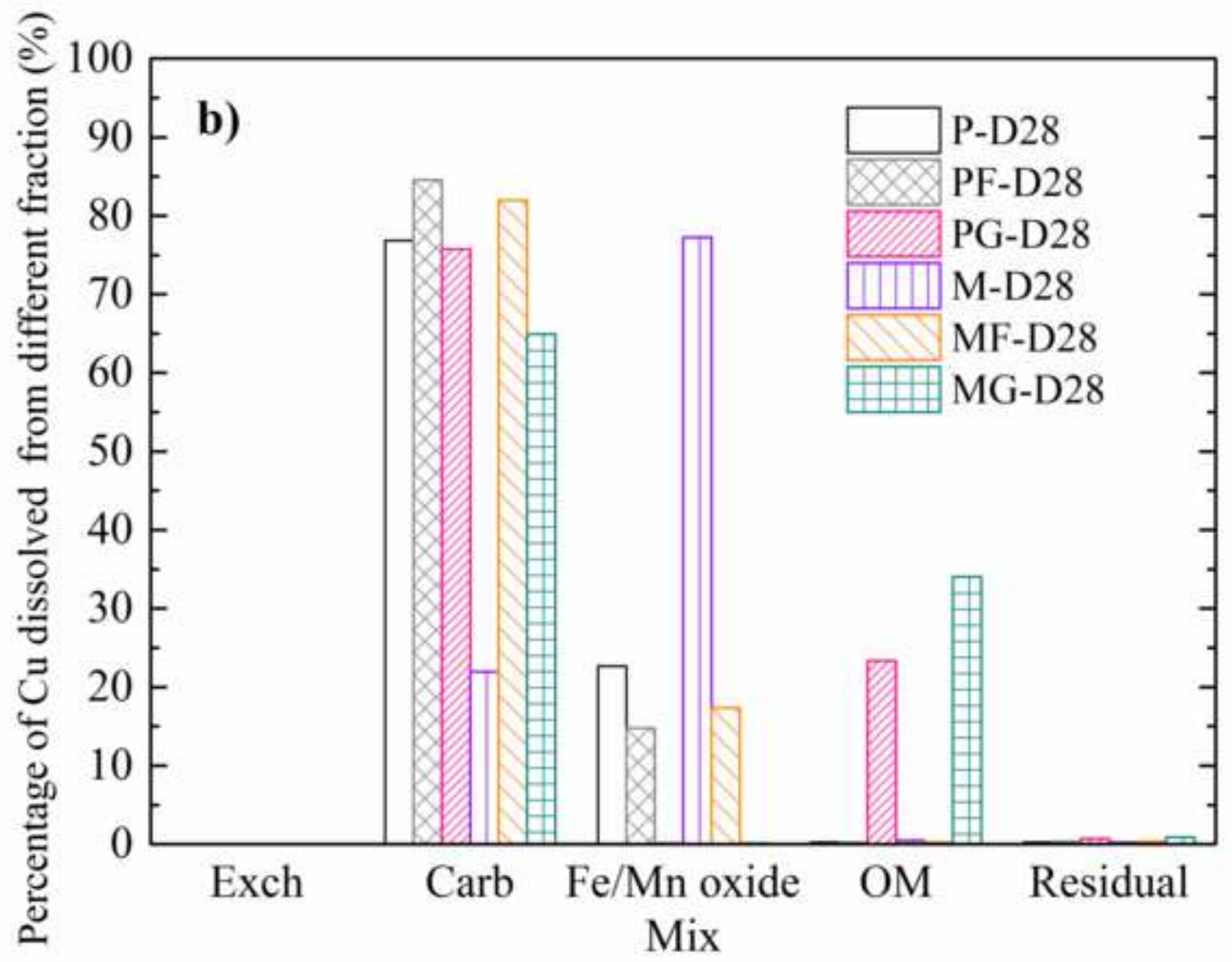




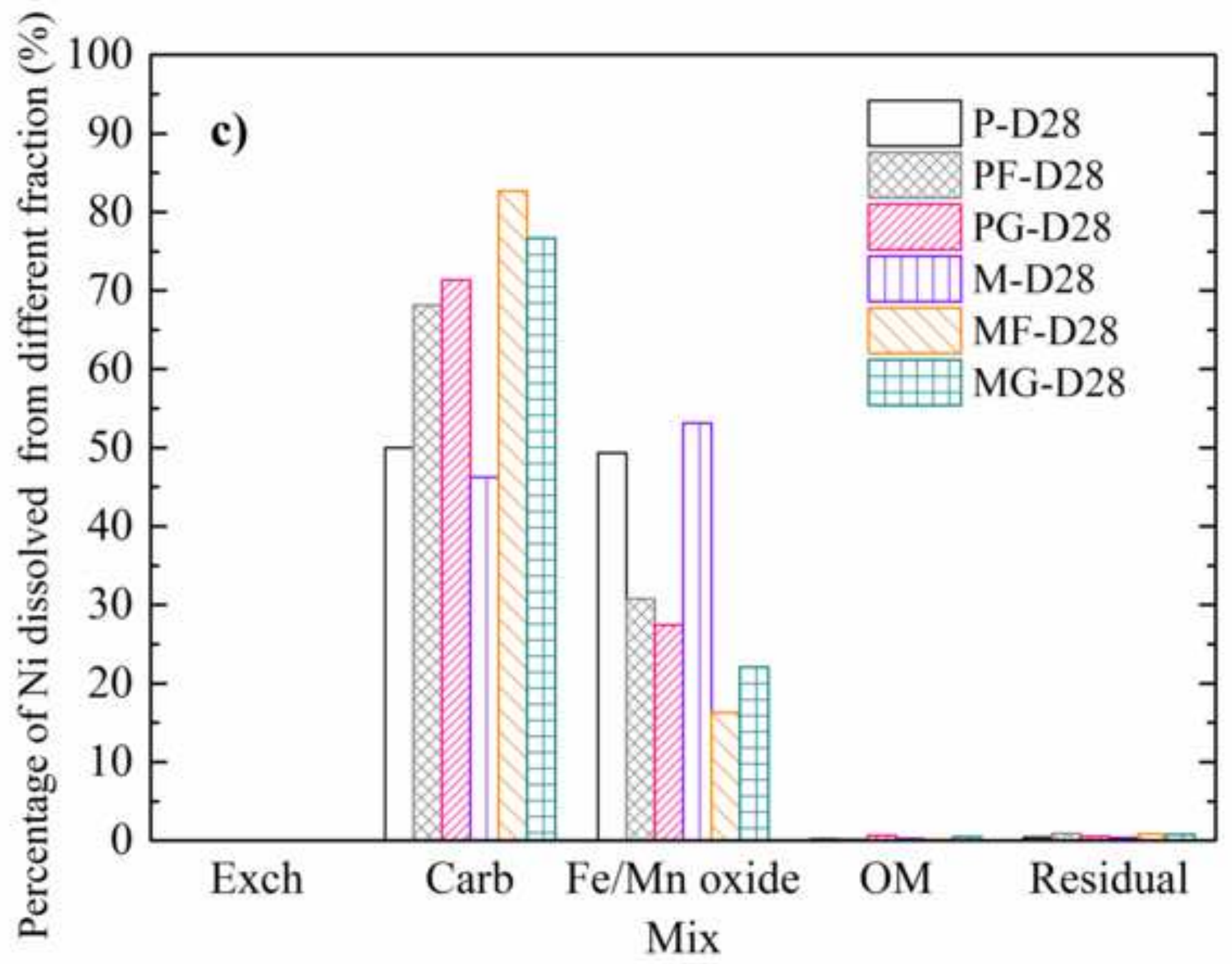




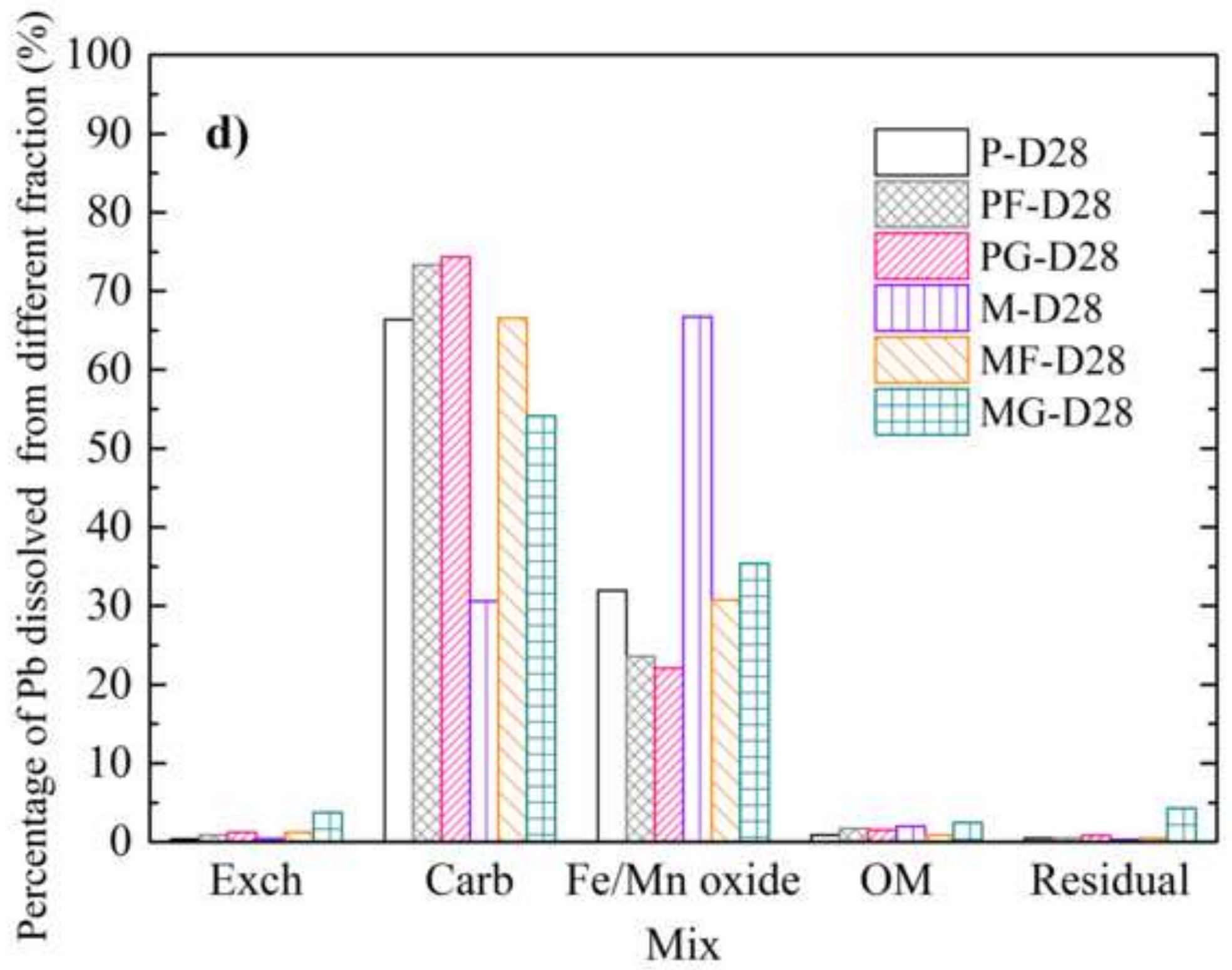




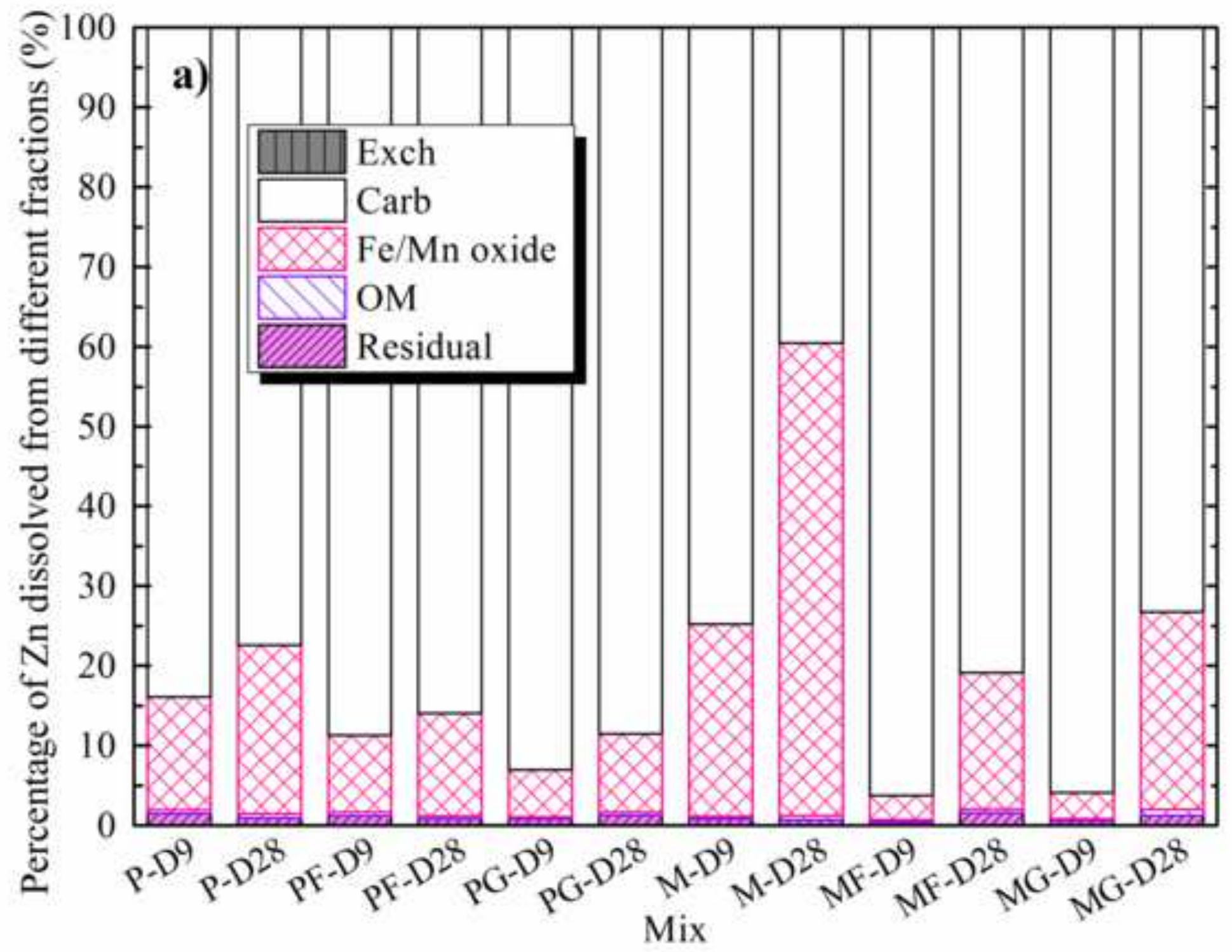




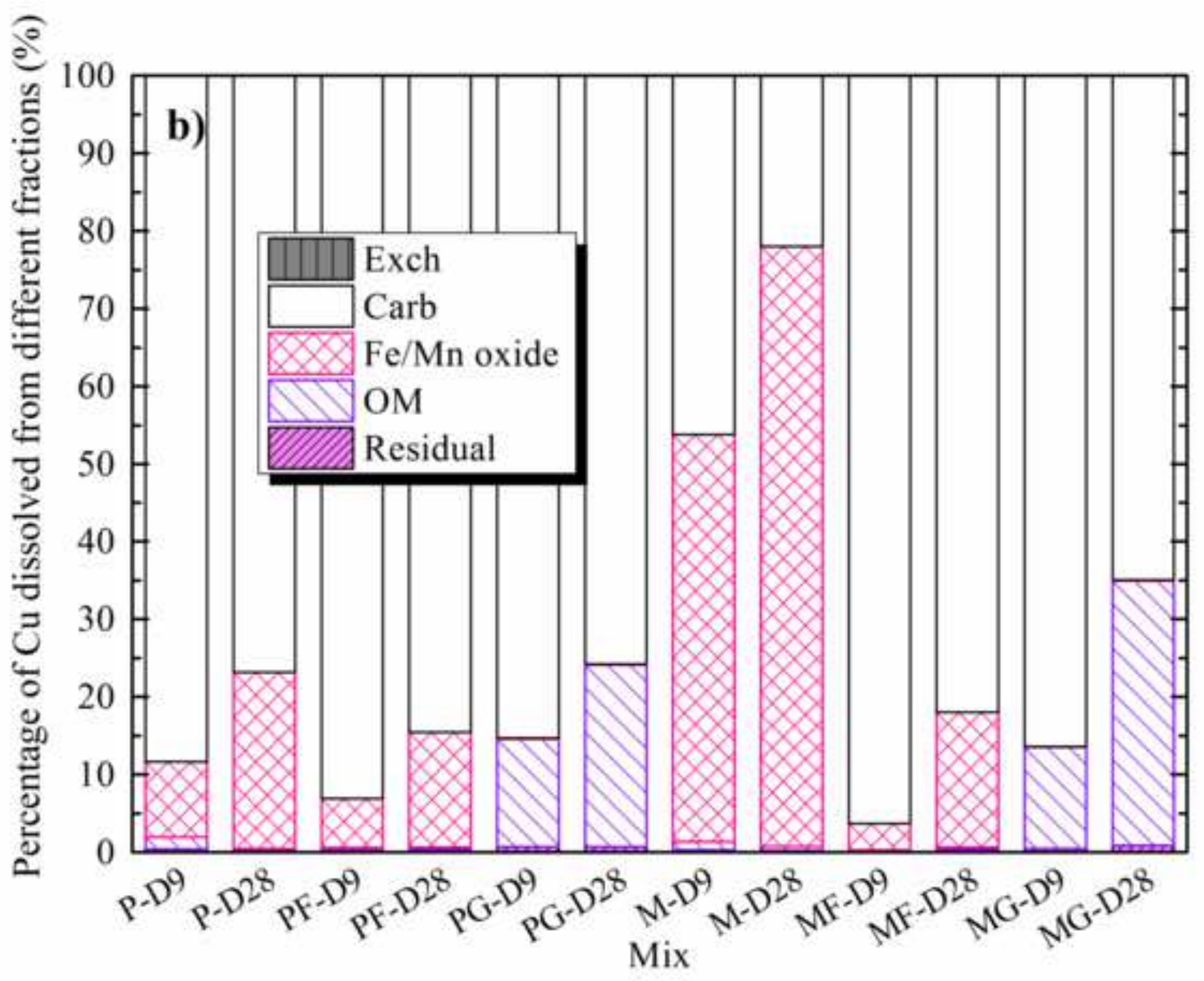




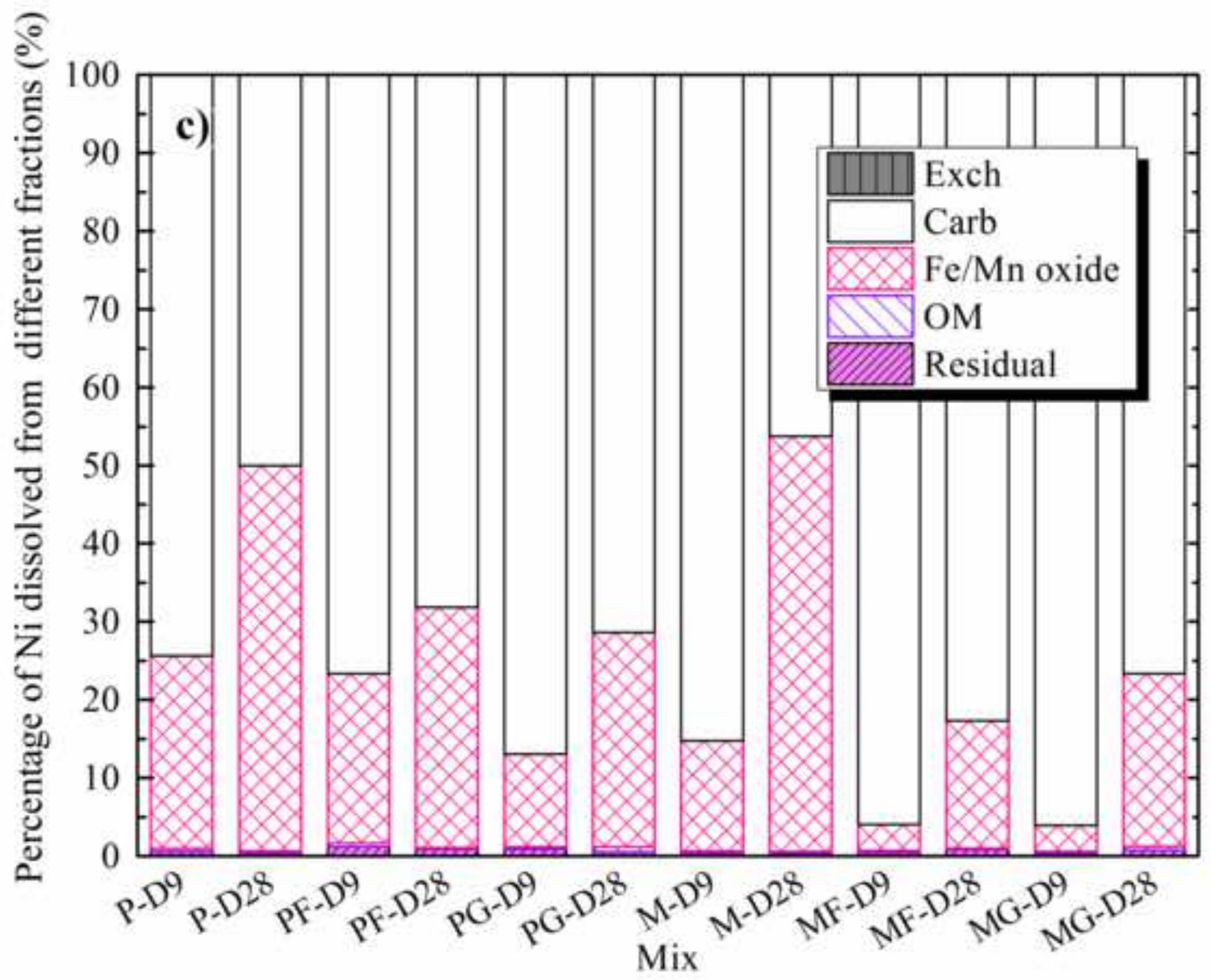




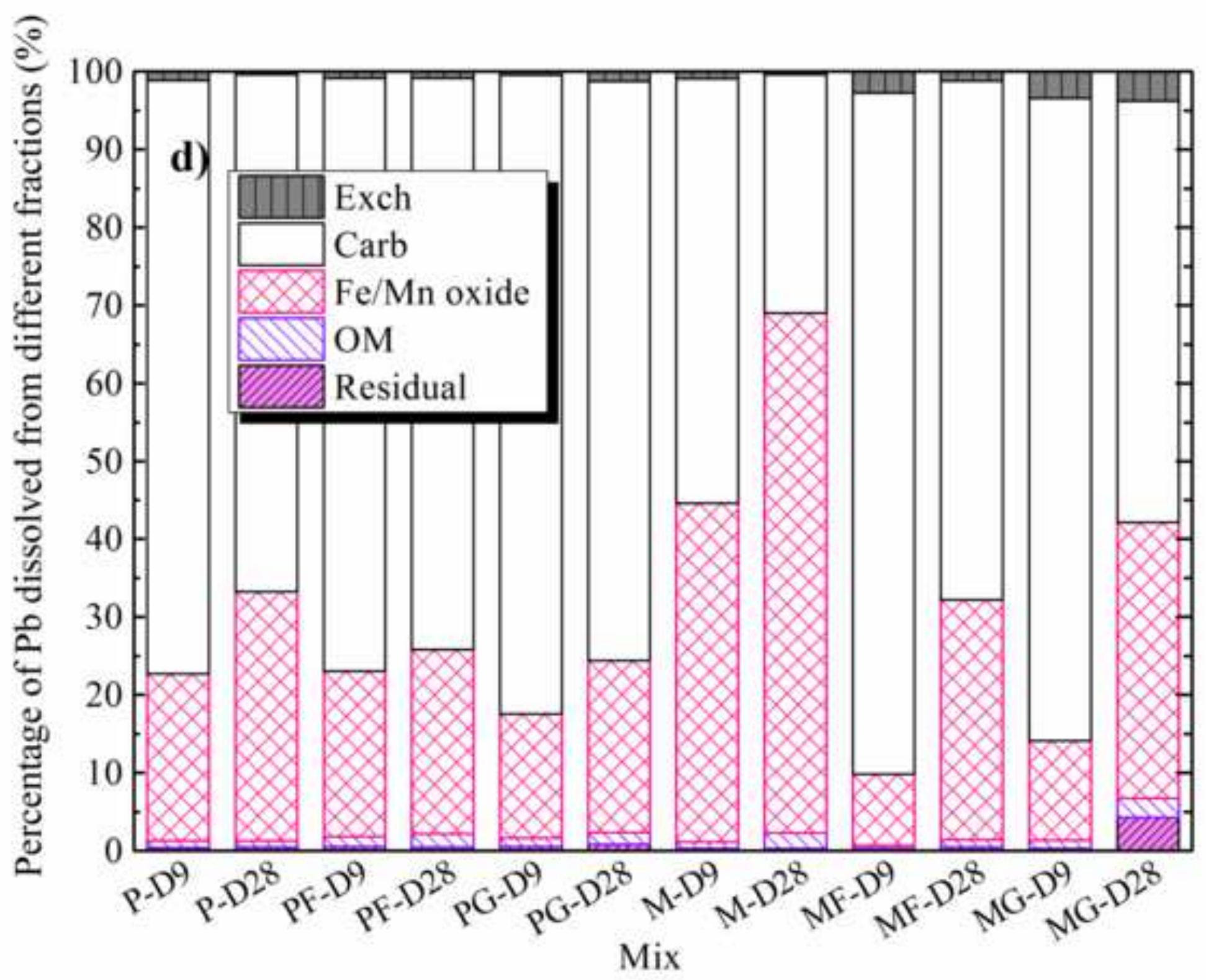

